\title{
Prenatal hepatitis B screening, and hepatitis B burden among children, in Ontario: a descriptive study
}

\author{
Mia J. Biondi NP-PHC PhD, Alex Marchand-Austin MSc, Kirby Cronin BSc, Natasha Nanwa PhD, \\ Vithusha Ravirajan MPH, Erin Mandel MPH, Lee W. Goneau PhD, Tony Mazzulli MD, Hemant Shah MD MScCH, \\ Camelia Capraru MD, Harry L.A. Janssen MD PhD, Beate Sander RN PhD, Jordan J. Feld MD MPH
}

Cite as: CMAJ 2020 October 26;192:E1299-305. doi: 10.1503/cmaj.200290

\begin{abstract}
BACKGROUND: Ontario is 1 of 5 provinces that immunize adolescents for hepatitis B virus (HBV), despite the World Health Organization recommendation for universal birth dose vaccination. One rationale for not vaccinating at birth is that universal prenatal screening and related interventions prevent vertical transmission. The aims of our study were to evaluate the uptake and epidemiology of prenatal HBV screening, and to determine the number of children in Ontario with a diagnosis of $\mathrm{HBV}$ before adolescent vaccination.
\end{abstract}

METHODS: We extracted data from ICES, Public Health Ontario and Better Outcomes \& Registry Network (BORN)
Ontario databases. We assessed prenatal screening uptake and prevalence of prenatal hepatitis $B$ surface antigen (HBsAg) from 2012 to 2016, as well as subsequent hepatitis $B$ e-antigen (HBeAg) and HBV DNA testing and percent positivity. We used age and region to subcategorize the results. In a separate unlinked analysis, we evaluated the number of children positive for HBV aged 0-11 years who were born in Ontario from 2003 to 2013.

RESULTS: From 2012 to 2016, 93\% of pregnant women were screened for $\mathrm{HBV}$, with an $\mathrm{HBsAg}$ prevalence of $0.6 \%$. Prevalence of $\mathrm{HBsAg}$ increased with age, peaking at older than 45 years at $3 \%$.
North Toronto had the highest overall prevalence of $1.5 \%$, whereas northern Ontario had the lowest. Of women who were $\mathrm{HBsAg}$ positive, $\mathrm{HBeAg}$ and $\mathrm{HBV}$ DNA tests were subsequently ordered in $13 \%$ and $38 \%$, respectively. Of children born in Ontario between 2003 and 2013, 139 of 23759 tested positive for HBV.

INTERPRETATION: Prenatal HBV screening is not universal and subsequent evaluation is poor, limiting optimal intervention and possibly contributing to some Ontario-born children being given a diagnosis of HBV before age 12 years. These findings underscore the limitations of the province's adolescent vaccination strategy.
A n estimated 257 million people are chronically infected with hepatitis B virus (HBV) worldwide. ${ }^{1}$ Hepatitis B ranks fourth on the list of most burdensome infectious diseases in Ontario, ${ }^{2}$ given the high risk of cirrhosis and liver cancer among people with chronic infection. The outcome of $\mathrm{HBV}$ infection is dependent on the age of exposure; more than $90 \%$ of neonates develop chronic infection, whereas rates of spontaneous clearance in immunocompetent adults are higher than $95 \%{ }^{3}$ Globally, vertical transmission remains a predominant route of transmission; as such, early prenatal screening for hepatitis B surface antigen ( $\mathrm{HBsAg}$ ) is recommended in Canada. ${ }^{4}$ Universal antenatal screening is especially important as Canada remains a destination country for newcomers from HBV-endemic regions. ${ }^{5}$
Interventions exist to decrease the possibility of HBV vertical transmission. The use of HBV vaccination within 24 hours of birth, with 2 additional doses in infancy, has been shown to be $90 \%$ effective in preventing transmission; ${ }^{6}$ the risk is further reduced by the administration of hepatitis $B$ immunoglobulin. ${ }^{7}$ In addition, for women who are HBV e-antigen (HBeAg) positive with high HBV DNA levels, antiviral therapy during the third trimester of pregnancy is recommended. 4,8

In 2009, the World Health Organization expanded universal birth dose vaccine recommendations to low-endemic countries, such as Canada. ${ }^{9}$ However, only 3 Canadian provinces and territories provide birth dose vaccination against HBV; 5 vaccinate starting at 2 months; and 5 provinces, including Ontario, vaccinate children between grades 6 and $7 .{ }^{10}$ The rationale for the latter 
approach is based on the following assumptions: pregnant women are universally screened; all infants born to mothers who test positive for HBsAg receive postexposure prophylaxis; sexual contact is the only other major risk factor; and waning immunity after infant vaccination could leave individuals unprotected as adults.

The objectives of our study were to better understand the uptake and epidemiology of prenatal HBV screening in Ontario, and to compare HBV acquisition in Canadian-born and non-Canadianborn children in Ontario before adolescent vaccination.

\section{Methods}

\section{Prenatal HBV testing data sources and linkage}

To facilitate universal prenatal testing for $\mathrm{HBsAg}$ as recommended by the Society for Obstetrics and Gynaecology Canada, Public Health Ontario has created a standardized prenatal requisition that includes HBsAg, HIV, syphilis and rubella screening. The data in our study include results from this order set, as well as HBsAg testing where prenatal or antenatal testing was specified. We used aggregate data from the Better Outcomes Registry and Network (BORN) Ontario, which captures all live and still births, to calculate age-, region- and year-specific screening uptake and prevalence. We determined the region based on the maternal postal code or postal code of the ordering provider if maternal postal code was not given, and aggregated data by Local Health Integration Network (LHIN). ${ }^{11}$ We extracted data from the Public Health Ontario Laboratory (PHOL) Laboratory Information Management System related to specimens received from Jan. 1, 2012 to Dec. 31, 2016. We included HBsAg, HBeAg and HBV DNA test results. We used Ontario Health Insurance Plan (OHIP) numbers to identify unique individuals. We categorized age into the following bands: younger than 15, 15-20, 21-25, 26-30, 31-35, 36-40, 41-45, and older than 45 years. We excluded individuals with no OHIP number and non-Ontario postal codes.

We filtered the raw laboratory data to remove duplicate testing and retain only specimens for which "prenatal" was indicated in the specimen record. We used a 259-day period to estimate the pregnancy window ( $37 \mathrm{wk}$ ), and removed HBsAg test repeats within each pregnancy. In cases of discordant duplicate results, we counted the positive result.

We linked $\mathrm{HBsAg}$-positive specimen records separately to $\mathrm{HBeAg}$ and $\mathrm{HBV}$ DNA results. We linked $\mathrm{HBeAg}$ and HBV DNA results only if the date of specimen receipt was 259 days or less from the date of specimen receipt for HBsAg testing. In cases where more than $1 \mathrm{HBeAg}$ or HBV DNA result was linked, we kept only the earliest result after the positive HBsAg for each test.

\section{Comparison of HIV and HBV prenatal testing}

Universal prenatal testing for HIV is recommended and included on the standardized Public Health Ontario prenatal requisition. In Ontario, the prevalence of both HBV and HIV is relatively low among the prenatal population, but both are included in routine screening because of the potential to intervene and prevent or reduce the probability of vertical transmission. Thus, in order to provide a comparison for HBsAg screening uptake, we assessed
HIV prenatal testing uptake using the same data acquisition and analysis methodology as described above, over the same time period (2012-2016), as previous studies have shown high uptake of HIV testing despite low prevalence. ${ }^{12}$

\section{Pediatric HBV testing data sources}

Children aged $0-11$ years who were tested for HBV between Jan. 1, 2003 and Dec. 31, 2013 formed our pediatric cohort. Public Health Ontario Laboratory HBV specimens were linked to health administrative data housed at ICES. ICES is an independent, nonprofit research institute whose legal status under Ontario's health information privacy law allows it to collect and analyze health care and demographic data, without patient consent, for health system evaluation and improvement. Using the Immigration, Refugee and Citizenship Canada Permanent Residents database, we stratified children into non-Canadian-born i.e., landing date recorded in the Citizenship and Immigration Canada database - and Canadian-born individuals. Currently, the Canadian Paediatric Society recommends universal screening of all children born outside Canada, once arrived. ${ }^{13}$ Data sets were linked using unique encoded identifiers and analyzed at ICES. The case definition for an HBV diagnosis was a positive HBsAg, a positive HBeAg or detectable HBV DNA. ${ }^{14}$ The index date was the date of the first positive HBV specimen, while for the rest of the cohort, the index date was based on the date of their first negative HBV specimen. Specimen results that were within 90 days of each other were combined, before categorizing the specimens as positive or negative.

\section{Statistical analysis}

We determined the $95 \%$ confidence intervals (Cls) of the proportions of antenatal HBV testing uptake and prevalence of HBV and HIV infection between 2012 and 2016 using the Clopper-Pearson (Exact) method.

\section{Ethics approval}

The University Health Network Research Ethics Board and Public Health Ontario Ethics Review Board approved the collection of prenatal anonymous, aggregate, linked data. ICES's collection of pediatric data was authorized under section 45 of Ontario's Personal Health Information Protection Act, which does not require review by a Research Ethics Board.

\section{Results}

\section{Prenatal HBsAg screening and follow-up testing}

HBsAg testing was performed in 92.7\% (Appendix 1, supplemental Figure 1, available at www.cmaj.ca/lookup/doi/10.1503/ cmaj.200290/tab-related-content) of pregnancies in Ontario from 2012 to 2016. The prevalence of HBsAg positivity was $0.63 \%$ among the 651745 tests performed. Linked data within the same pregnancy showed that $\mathrm{HBeAg}$ testing was performed in $13.2 \%$ (range between the different age bands 10.1-15.2 yr) of women who were $\mathrm{HBsAg}$ positive, with $18.9 \%$ testing $\mathrm{HBeAg}$ positive. HBV DNA follow-up testing was performed in $37.9 \%$ (range between the age bands 34.6-43.6 yr) of women who 
were HBsAg positive, of whom 95.8\% had detectable DNA (summarized in Appendix 1, supplemental Figure 2). In 2017, the Society of Obstetrics and Gynaecology Canada began to recommend the use of third-trimester antivirals to reduce the risk of vertical transmission for women with HBV DNA levels above $200000 \mathrm{lU} / \mathrm{mL}^{4}{ }^{4}$ Of women who were tested for HBV DNA and had a detectable viral load, $17.5 \%(n=273)$ would have met the criteria for treatment. The likelihood of HBV DNA levels being above the treatment threshold decreased with age among those with a completed HBV DNA test $(27.7 \%<26 \mathrm{yr}$ to $6.7 \%$ $>40 \mathrm{yr}$ ) (Figure 1).

HBsAg positivity increased with age (Table 1), peaking among women older than 45 years, at $2.97 \%(n=1551)$; a prevalence of $5 \%(n=475)$ was reported in this age group in the Central and Central East LHINs (Table 2). The Central and Central East LHINs also had the highest overall prevalence of $\mathrm{HBsAg}$ at $1.5 \%$ and $1.1 \%$, respectively (Figure 2). Uptake of follow-up HBV DNA testing varied greatly by LHIN, from $8 \%(95 \% \mathrm{Cl} 4.95-12.1)$ to $46 \%$ (95\% Cl 43.4-48.8), which was not the case for HBsAg testing uptake (data not shown).

\section{Comparison of prenatal HIV and HBV screening and prevalence}

We found that prenatal HIV testing was performed in $95.6 \%$ of pregnancies, and of the 671979 HIV tests (unique pregnancies) performed, $0.03 \%$ were positive.

\section{Canadian-born children positive for HBV}

Table 3 shows the number of Canadian- and non-Canadian-born children aged $0-11$ years tested and diagnosed with HBV between 2003 and 2013. In this period, 23759 Canadian-born children were tested for HBsAg, compared with 3221 non-Canadian-born children. Although more foreign-born than Canadian-born children tested positive per 1000 tested ( 24 v. 6 per 1000 tested), the absolute number of Canadian-born children diagnosed with HBV before age $12(n=139)$, and thus their contribution to the overall pediatric HBV burden in the province, was greater than the number of foreign-born children who tested positive $(n=76)$.

\section{Interpretation}

We found that prenatal screening for HBV in Ontario between 2012 and 2016 was imperfect at 92.7\%. Furthermore, at least 139 children born in Ontario between 2003 and 2013 were infected with HBV before being eligible for adolescent vaccination, which highlights deficiencies in the current vaccine strategy in Ontario. The National Advisory Committee on Immunization states, "Epidemiological information demonstrating failure of universal prenatal screening and routine immunization programs (i.e., detection of HBV infection in infants and children awaiting immunization) should be collected and analyzed on an ongoing basis, so that appropriate changes can be made to existing HB immunization programs as needed." 15 Although it is difficult to extrapolate from our findings to estimate the total number of cases that could have been prevented by a strategy of universal birth dose vaccination because of the low proportion of children tested and the unknown reasons for testing, our findings suggest that the Ontario HBV vaccine policy should be reassessed.

While universal HBV prenatal screening is recommended across Canada to prevent vertical transmission of infection, a recent study in Quebec showed that when vaccination status was

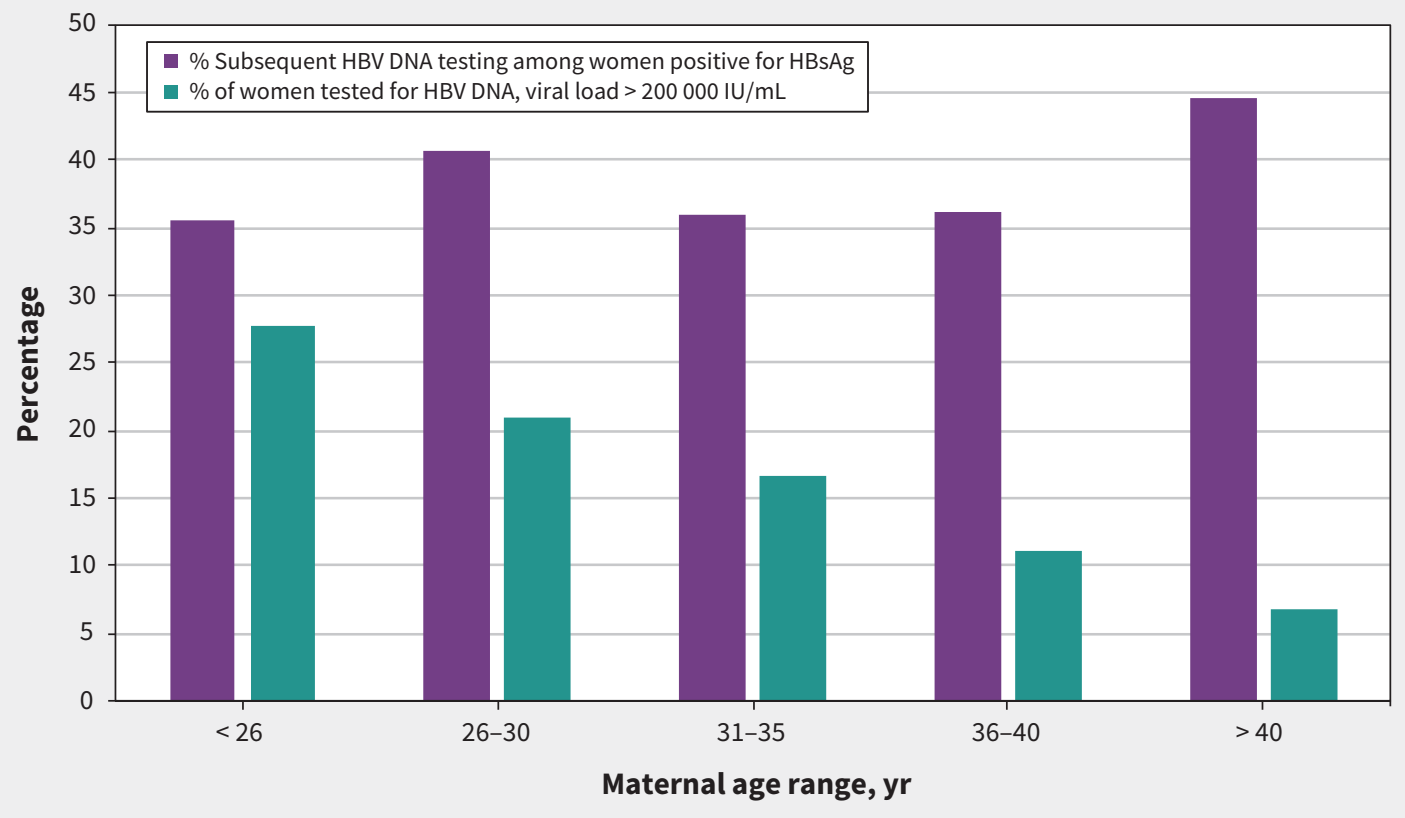

Figure 1: Hepatitis B virus (HBV) DNA subsequent testing and viral loads $>200000 \mathrm{IU} / \mathrm{mL}$, by age. Note: $\mathrm{HBSAg}=$ hepatitis B surface antigen. 


\begin{tabular}{|c|c|c|c|c|}
\hline $\begin{array}{l}\text { Age group, } \\
\text { yr }\end{array}$ & $\begin{array}{l}\text { No. of women } \\
\text { tested for HBsAg }\end{array}$ & $\begin{array}{c}\text { HBsAg } \\
\text { prevalence, \% } \\
(95 \% \mathrm{Cl})\end{array}$ & $\begin{array}{l}\text { HBeAg positivity, } \\
\%^{\star}\end{array}$ & $\begin{array}{c}\text { HBV DNA } \\
\text { positivity, \%† }\end{array}$ \\
\hline$<15$ & 747 & $0.40(0.08-0.12)$ & Data suppressed $\ddagger$ & Data suppressed $\ddagger$ \\
\hline $15-20$ & 30772 & $0.07(0.05-0.11)$ & 0.0 & 100.0 \\
\hline $21-25$ & 97619 & $0.40(0.36-0.44)$ & 26.3 & 96.5 \\
\hline $26-30$ & 209978 & $0.62(0.59-0.66)$ & 25.1 & 96.1 \\
\hline $31-35$ & 208536 & $0.67(0.63-0.70)$ & 17.3 & 95.6 \\
\hline $36-40$ & 86891 & $0.87(0.81-0.93)$ & 11.0 & 96.0 \\
\hline $41-45$ & 15651 & $1.17(1.01-1.35)$ & 5.9 & 92.9 \\
\hline$>45$ & 1551 & $2.97(2.18-3.94)$ & 0.0 & 93.8 \\
\hline All & - & $0.63(0.61-0.65)$ & 18.9 & 95.8 \\
\hline
\end{tabular}

Note: $\mathrm{Cl}=$ confidence interval, $\mathrm{HBeAg}=$ hepatitis $\mathrm{B}$ e-antigen, $\mathrm{HBsAg}=$ hepatitis $\mathrm{B}$ surface antigen, $\mathrm{HBV}=$ hepatitis $\mathrm{B}$ virus. ${ }^{*} \mathrm{HBeAg}$ positivity rate is only among those who are $\mathrm{HBsAg}$ positive and tested for $\mathrm{HBeAg}$. THBV DNA positivity rate is only among those who are HBsAg positive and tested for HBV DNA.

$\ddagger$ Data suppressed as per rules of reporting by ICES for small cell numbers to avoid possible identification.

\section{Table 2: Prevalence of prenatal HBsAg by maternal age in high-prevalence Local} Health Integration Networks*

\begin{tabular}{|c|c|c|c|}
\hline \multirow{2}{*}{$\begin{array}{l}\text { Age group, } \\
\text { yr }\end{array}$} & \multicolumn{3}{|c|}{ HBsAg positivity, $\%(95 \% \mathrm{CI})$} \\
\hline & Central East & Central & Toronto Central \\
\hline$<15$ & 0.00 & $1.15(0.03-6.24)$ & $1.35(0.03-0.7 .30)$ \\
\hline $15-20$ & $0.13(0.04-0.33)$ & $0.20(0.05-0.51)$ & $0.37(0.12-0.87)$ \\
\hline $21-25$ & $0.85(0.69-1.04)$ & $1.18(0.97-1.43)$ & $1.25(1.00-1.59)$ \\
\hline $26-30$ & $1.29(1.15-1.44)$ & $1.66(1.51-1.82)$ & $0.85(0.71-1.01)$ \\
\hline $31-35$ & $0.99(0.86-1.13)$ & $1.43(1.30-1.57)$ & $0.74(0.64-0.85)$ \\
\hline $36-40$ & $1.21(0.99-1.45)$ & $1.62(1.43-1.84)$ & $0.86(0.71-1.04)$ \\
\hline $41-45$ & $1.54(1.01-2.25)$ & $2.07(1.59-2.64)$ & $1.22(0.82-1.75)$ \\
\hline$>45$ & $5.14(2.38-9.54)$ & $5.00(2.83-8.11)$ & $2.06(0.67-4.74)$ \\
\hline All & $1.08(1.01-1.16)$ & $1.51(1.43-1.60)$ & $0.85(0.78-0.93)$ \\
\hline
\end{tabular}

known, only $72 \%$ of pregnant women were tested for HBsAg. ${ }^{16}$ In Ontario, prenatal care is provided by primary care physicians and nurse practitioners, midwives and obstetricians, often in combination. Yet, there is no centralized database to ensure initial and follow-up screening is occurring, nor whether children born to mothers positive for HBV receive postexposure prophylaxis. Importantly, many other provinces have centralized provincial databases for vaccination records, but Ontario continues to lag in this regard, making it difficult to understand whether children born in Canada acquired HBV as a result of vaccine failure or noncompletion, a lack of maternal HBV screening, or whether a caregiver was a household contact and not identified.

We found that prenatal HBV testing occurred less often than HIV screening, suggesting that achieving high uptake is possible and that lower HBV screening rates may relate to poor screening implementation rather than a fundamental barrier. The fact that the prenatal prevalence of HBV is markedly higher than HIV, yet HIV screening is more consistently performed, suggests that chronic viral hepatitis ( $\mathrm{B}$ and $\mathrm{C}$ virus) may be downplayed compared with HIV. ${ }^{2}$

Furthermore, we found low rates of follow-up testing within the prenatal period for women who tested HBsAg positive, which varied greatly by region in Ontario, with 1 LHIN reporting HBV follow-up DNA testing of only $8 \%$. HBeAg and HBV DNA testing are required to determine the need for prenatal antiviral therapy to reduce the risk of transmission and are important for subsequent maternal HBV follow-up after delivery. In our study, 273 women met the criteria for third trimester antiviral treatment. However, 


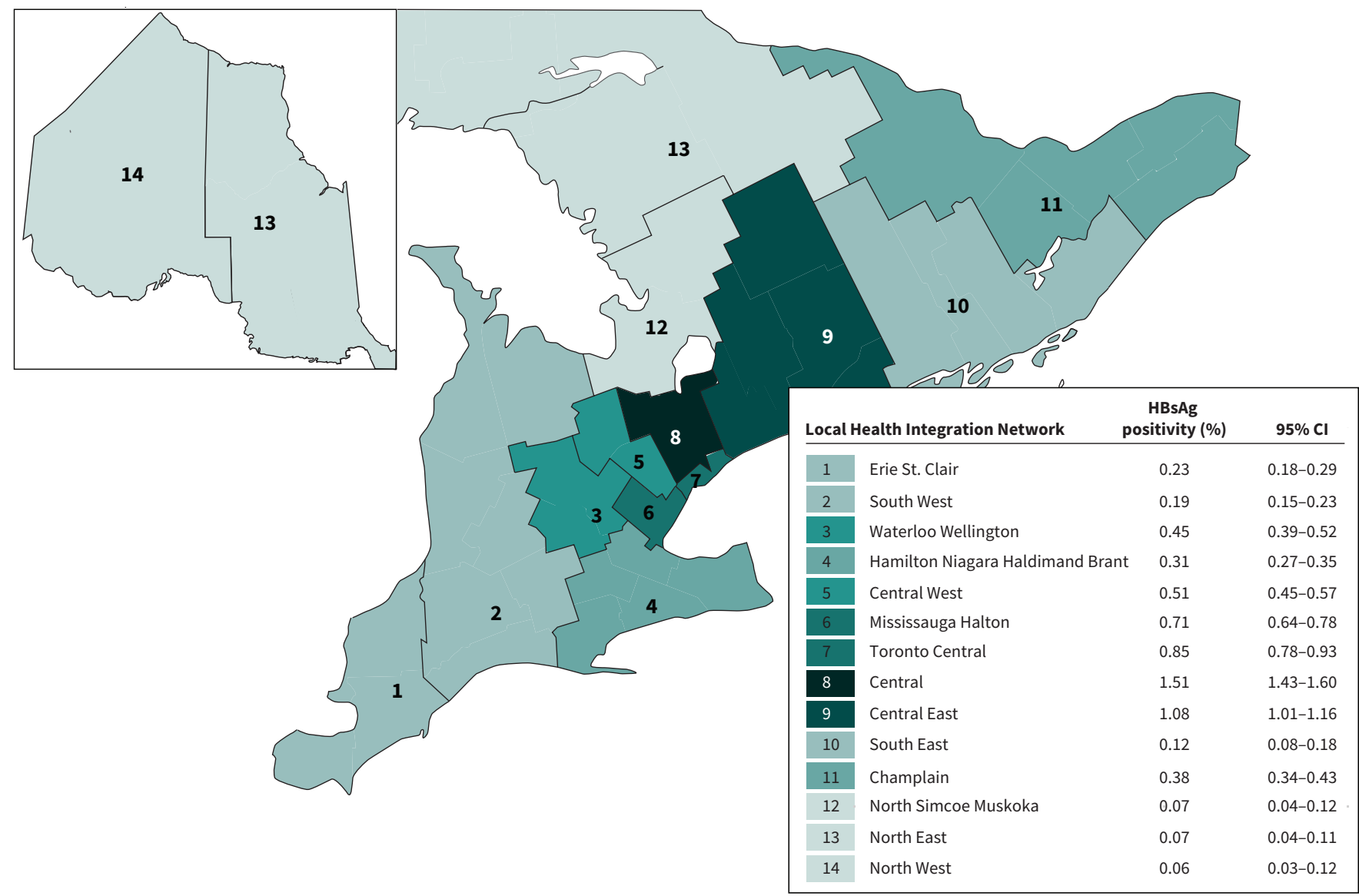

Figure 2: Prevalence of prenatal hepatitis B among those screened 2012-2016, by Ontario region. Note: $\mathrm{Cl}=$ confidence interval, $\mathrm{HBSAg}=$ hepatitis B surface antigen.

\begin{tabular}{|c|c|c|c|c|c|c|c|c|c|}
\hline \multirow[b]{2}{*}{$\begin{array}{l}\text { Age groups, } \\
\text { yr }\end{array}$} & \multicolumn{3}{|c|}{ Canadian-born } & \multicolumn{3}{|c|}{ Foreign-born } & \multicolumn{3}{|c|}{ Combined } \\
\hline & Tested & Positive & $\begin{array}{c}\text { Cases } \\
\text { per } 1000\end{array}$ & Tested & Positive & $\begin{array}{c}\text { Cases } \\
\text { per } 1000\end{array}$ & Tested & Positive & $\begin{array}{c}\text { Cases } \\
\text { per } 1000\end{array}$ \\
\hline $0-3$ & 12134 & 73 & 6 & 767 & 7 & 9 & 12901 & 80 & 6 \\
\hline $4-7$ & 5984 & 30 & 5 & 953 & 26 & 27 & 6937 & 56 & 8 \\
\hline $8-11$ & 5641 & 36 & 6 & 1501 & 43 & 29 & 7142 & 79 & 11 \\
\hline Total & 23759 & 139 & 6 & 3221 & 76 & 24 & 26980 & 215 & 8 \\
\hline
\end{tabular}

only $37.9 \%$ of women positive for HBsAg were tested for HBV DNA. If a similar proportion of women had met treatment criteria among those not tested for HBV DNA, 447 women may have missed additional interventions.

Universal adolescent vaccination for HBV began in a school-based setting in Ontario in 1997, with one rationale for vaccinating at this time being the potential for waning immunity in adulthood, leaving individuals unprotected or requiring a booster. However, long-term follow-up studies from Asia have shown no significant waning immunity, with a similar risk of infection in adulthood of individuals vaccinated at birth compared with vaccination in adolescence. ${ }^{17-19}$ Furthermore, the consequences of HBV acquisition in adulthood are relatively low, given the high rate of spontaneous clearance of HBV among newly infected adults. ${ }^{3}$

A recent publication showed that only $86.3 \%$ of 17 -year-olds in Ontario had received 1 or more HBV immunization doses, ${ }^{20}$ and from 2013-2018, the average vaccination coverage among 
those aged 12 years was $70.0 \%$ (range for years $68.6-71.7$ ), with some public health units reporting rates as low as $50 \%-60 \%$ in 2017-2018. ${ }^{21}$ Thus, even in the context of adolescent vaccination, coverage is suboptimal.

In 1991, the United States introduced universal birth dose vaccination, and catch-up vaccination for children and adolescents, ${ }^{22}$ with widespread acceptance by $1996 .{ }^{23}$ Between 1993 and 2000, vaccination rates among children aged 19-35 months went from $16 \%$ to $90 \%,{ }^{24}$ and $90 \%$ of children born to a mother positive for HBV infection have received hepatitis B immunoglobulin and birth dose vaccination. ${ }^{24}$ This strategy appears to have been effective, as acute HBV infection in children aged 1-9 years declined by more than $80 \%$ from 1986 to $2000 .{ }^{24}$ Birth dose vaccination is particularly important in Canada, given the relatively high foreign-born population from HBV-endemic countries. Birth dose vaccination would ensure that infants are protected from HBV acquisition if maternal screening is missed, but would also protect them from infection from other household contacts or caregivers, some of whom may not be aware of their HBV status. Preventing childhood infection is critical to prevent the longterm consequences of chronic HBV infection.

Our observation that 139 children born in Ontario were found to be HBsAg positive before age 12 years strongly suggests that the infection occurred either because of lack of postexposure interventions if these children were born to mothers positive for $\mathrm{HBsAg}$ who were not screened, or that HBV was acquired from other household contacts such as fathers, ${ }^{25}$ grandparents or other caregivers. In any case, these infections likely would have been prevented if universal birth dose vaccination was the standard of care. It is recommended to vaccinate all household contacts of individuals with HBV infection, yet no comprehensive system exists to vaccinate children living with carriers of HBV. Indeed, the 139 children who received the diagnosis before adolescent vaccination represents a minimum number for the province, because diagnosis requires testing and not all pre-adolescent children are tested.

\section{Limitations}

Time frames for data acquisition were related to availability of high-quality data. Notably, we were unable to acquire pediatric data later than 2013, as the Ontario Provincial Laboratory is not yet linked past this date, and high-quality $\mathrm{PHOL}$ data were not available until 2010, while BORN Ontario data were not available until 2012. Although the BORN Ontario database is the most comprehensive obstetric data source in Ontario, it does not capture pregnancies that lead to spontaneous or planned abortions or multiple gestations. Additionally, testing could occur within 2 different pregnancies within the 259-day window, leading to underreporting as the result of our excluding the second HBsAg test. Administrative data from both PHOL and ICES have additional limitations, including missing data, which may slightly underestimate or overestimate reporting. Finally, a centralized database does not exist to determine hepatitis B immunoglobulin or HBV vaccine doses given to high-risk infants, and our administrative database does not capture these interventions. This limits our ability to determine the source of infection in the Canadian-born children found to be HBsAg positive before adolescent vaccination.

\section{Conclusion}

Prenatal HBV screening in Ontario is not universal and follow-up testing after a positive $\mathrm{HBsAg}$ test is low, leaving the potential for vertical HBV transmission. The number of children born in Ontario who tested positive for HBsAg before adolescent vaccination suggests that the current vaccine policy in Ontario is suboptimal. These data support adopting birth dose HBV vaccination in Ontario and reflex HBeAg and HBV DNA testing for women who test HBsAg positive (testing on initial positive HBsAg sample), and establishing data collection tools for hepatitis B immunoglobulin and vaccinations to ensure that HBV transmission is minimized in the province.

\section{References}

1. Global hepatitis report 2017. Geneva: World Health Organization; 2017. Available: https://apps.who.int/iris/bitstream/handle/10665/255016/9789241565455-eng.pdf; jsessionid=5D96C02E65D3C16C43712E05ABB8EE41? sequence $=1$ (accessed 2019 Oct. 26).

2. Kwong JC, Ratnasingham S, Campitelli MA, et al. The impact of infection on population health: results of the Ontario burden of infectious diseases study. PLoS One 2012; 7:e44103.

3. Hepatitis B [fact sheet]. Geneva: World Health Organization; 2019. Available: www.who.int/news-room/fact-sheets/detail/hepatitis-b (accessed 2019 Oct. 26).

4. Castillo E, Murphy K, van Schalkwyk J. No. 342: hepatitis B and pregnancy. J Obstet Gynaecol Can 2017;39:181-90.

5. Immigration and ethnocultural diversity highlight tables: immigrant status and period of immigration, 2016 counts, both sexes, age (total), Canada, provinces and territories, 2016 Census - 25\% Sample data [table]. Ottawa: Statistics Canada; modified 2019 Feb. 20. Available: www12.statcan.gc.ca/census-recensement/ 2016/dp-pd/hlt-fst/imm/Table.cfm?Lang=E\&T=11\&Geo=00 (accessed 2019 Oct. 26).

6. Plotkin S, Orenstein W, Offit P. Vaccines, 6th edition. Philadelphia: Saunders; 2012.

7. Lee C, Gong Y, Brok J, et al. Effect of hepatitis B immunisation in newborn infants of mothers positive for hepatitis B surface antigen: systematic review and meta-analysis. BMJ 2006;332:328-36.

8. Brown RS Jr, McMahon BJ, Lok AS, et al. Antiviral therapy in chronic hepatitis B viral infection during pregnancy: a systematic review and meta-analysis. Hepatology 2016;63:319-33

9. Preventing perinatal hepatitis $B$ virus transmission: a guide for introducing and strengthening hepatitis B birth dose vaccination. Geneva: World Health Organization; 2015. Available: http://apps.who.int/iris/bitstream/10665/208278 /1/9789241509831_eng.pdf (accessed 2019 Nov. 10).

10. Provincial and territorial routine and catch-up vaccination schedule for infants and children in Canada [table]. Ottawa: Public Health Agency of Canada; modified 2020 May 13. Available: www.canada.ca/en/public-health/services/provincial -territorial-immunization-information.html (accessed 2019 Nov. 10).

11. Ontario's LHINs. Toronto: Queen's Printer for Ontario; 2014.

12. Remis RS, Merid MF, Palmer RW, et al. High uptake of HIV testing in pregnant women in Ontario, Canada. PLoS One 2012;7:e48077.

13 Medical assessment of immigrant and refugee children - checklist: initial assessment. Ottawa: Canadian Paediatric Society; updated 2015. Available: www.kids newtocanada.ca/e-checklist/initial-assessment (accessed 2019 Oct. 20).

14. Surveillance case definitions for current and historical conditions. Atlanta: Centers for Disease Control and Prevention; reviewed and update 2017 Aug. 2. Available: wwwn.cdc.gov/nndss/conditions/ (accessed 2019 Sept. 12).

15. Update on the recommended use of hepatitis B vaccine: an Advisory Committee Statement (ACS) National Advisory Committee on Immunization (NACI). Ottawa: Public Health Agency of Canada; 2017, modified 2019 Oct. 9. Available: www.canada.ca/en/public-health/services/publications/healthy-living/update -recommended-use-hepatitis-b-vaccine.html\#a5 (accessed 2019 Oct. 20).

16. Desjardins M, Boucoiran I, Paquet C, et al. Impact of vaccination history on serological testing in pregnant women. J Obstet Gynaecol Can 2018;40:405-9.

17. Ni Y-H. Natural history of hepatitis B virus infection: pediatric perspective. $J$ Gastroenterol 2011;46:1-8.

18. Yim HJ, Lok AS-F. Natural history of chronic hepatitis B virus infection: what we knew in 1981 and what we know in 2005. Hepatology 2006;43(Suppl 1):S173-81. 
19. Haber BA, Block JM, Jonas MM, et al. Hepatitis B Foundation. Recommendations for screening, monitoring, and referral of pediatric chronic hepatitis $B$. Pediatrics 2009;124:e1007-13.

20. Vaccine coverage in Canadian children: results from the 2013 Childhood National Immunization Coverage Survey (CNICS). Public Health Agency of Canada; 2017. Available: http://publications.gc.ca/collections/collection_2017/aspc-phac/ HP40-156-2017-eng.pdf (accessed 2019 Oct. 26).

21. Immunization coverage report for school pupils in Ontario: 2017-18 school year - techical report. Toronto: Public Health Ontario; 2019. Available: www. publichealthontario.ca/-/media/documents/I/2019/immunization-coverage -2017-18.pdf (accessed 2029 June 12).
22. Hepatitis B virus: a comprehensive strategy for eliminating transmission in the United States through universal childhood vaccination. Recommendations of the Immunization Practices Advisory Committee (ACIP). MMWR Recomm Rep 1991;40:1-25.

23. Freed GL, Freeman VA, Clark SJ, et al. Pediatrician and family physician agreement with and adoption of universal hepatitis B immunization. J Fam Pract 1996;42:587-92.

24. Centers for Disease Control and Prevention (CDC). Hepatitis B vaccination United States, 1982-2002. MMWR Morb Mortal Wkly Rep 2002;51:549-52, 63.

25. Tajiri H, Tanaka Y, Kagimoto S, et al. Molecular evidence of father-to-child transmission of hepatitis B virus. J Med Virol 2007;79:922-6.
Competing interests: Tony Mazzulli reports serving as a speaker, consultant or advisory board member for Merck, Pfizer, Qvella, Microbix, Roche, Verity Pharmaceuticals and Cipher Pharmaceuticals, and receiving research funding from Qvella and bioMérieux. Harry Janssen reports serving as a speaker, consultant or advisory board member for AbbVie, Arbutus, Benitec, Bristol Myers Squibb, Gilead Sciences, Glaxo, Janssen, Medimmune, Merck, Roche and Vir Biotechnology, and receiving research funding from AbbVie, Bristol Myers Squibb, Gilead Sciences, Janssen, Medimmune, Merck and Roche. Jordan Feld reports receiving research support or consulting fees from Abbott, AbbVie, Enanta, Gilead, Janssen, Roche, Arbutus and GlaxoSmithKline. No other competing interests were declared.

This article has been peer reviewed.

Affiliations: Viral Hepatitis Care Network Study Group/Toronto Centre for Liver Disease (Biondi, Mandel, Shah, Capraru, Janssen, Feld), University Health Network, Toronto, Ont.; Arthur Labatt Family School of Nursing (Biondi), Western University, London, Ont.; Public Health Ontario Laboratory (Marchand-Austin, Cronin, Ravirajan, Goneau, Mazzulli), Toronto, Ont.; National Microbiology Laboratory (Cronin), Public Health Agency of Canada, Winnipeg, Man.; Public Health Ontario (Nanwa, Ravirajan, Sander); ICES Central (Nanwa, Sander); Sinai Health System/ University Health Network (Mazzulli); Institute of Medical Sciences (Feld), University of Toronto, Toronto, Ont.

Contributors: Mia Biondi and Jordan Feld contributed to the conception and design of the work. Alex Marchand-Austin, Natasha Nanwa, Kirby Cronin, Vithusha Ravirajan, Beate Sander, Lee Goneau and Tony Mazzulli contributed to the acquisition of data. Mia Biondi and Jordan Feld contributed to the analysis and interpretation of data. Mia Biondi, Erin Mandel, Natasha Nanwa, Kirby Cronin, Camelia Capraru, Hemant
Shah, Harry Janssen and Jordan Feld drafted the manuscript. All of the authors revised it critically for important intellectual content, gave final approval of the version to be published and agreed to be accountable for all aspects of the work.

Data sharing: All data will be available to others upon review and approval of the "reason for request" by Mia Biondi and Jordan Feld. Requests for data should be sent to mia.biondi@mail.mcgill.ca or jordan.feld@uhn.ca.

Disclaimer: This study was supported by ICES, which is funded by an annual grant from the Ontario Ministry of Health and Long-Term Care (MOHLTC). The analyses, opinions, results and conclusions reported in this paper are those of the authors and are independent from the funding sources. No endorsement by ICES or the Ontario MOHLTC is intended or should be inferred. Parts of this study also received funding from by a Canadian Institutes of Health Research (CIHR) operating grant (grant number: MOP 130553, grant recipient: Beate Sander) and Public Health Ontario (PHO). $\mathrm{PHO}$ is funded by annual grants from the Ontario Ministry of Health and Long-Term Care (MOHLTC). The opinions, results, and conclusions reported in this article do not necessarily represent the views of $\mathrm{CIHR}, \mathrm{PHO}$, or the MOHLTC. This research was undertaken, in part, thanks to funding from the Canada Research Chairs program to Beate Sander. Parts of this material are based on data and/or information compiled and provided by the Canadian Institute for Health Information (ClHI). However, the analyses, conclusions, opinions and statements expressed in the material are those of the author(s), and not necessarily those of $\mathrm{CIHI}$.

Accepted: June 18, 2020

Correspondence to: Jordan Feld, jordan.feld@uhn.ca 